\title{
Conditions for the development of anaerobic digestion technologies using the organic fraction of municipal solid waste: perspectives for Poland
}

\author{
Anna Rolewicz-Kalińska ${ }^{1}$ - Anna Oniszk-Popławska ${ }^{2}$. \\ Judyta Wesołowska ${ }^{2}$ Elżbieta D. Ryńska
}

Received: 17 September 2015/ Accepted: 6 May 2016/Published online: 19 May 2016

(C) The Author(s) 2016. This article is published with open access at Springerlink.com

\begin{abstract}
This article outlines problems related to the location of facilities designed to treat the organic fraction of municipal solid waste (OFMSW). Anaerobic digestion (AD) facilities are investigated as a treatment option, while taking into account the aspects of renewable energy generation. This research has been spurred on by the relationship between waste management, energy generation issues and spatial planning procedures. The analysis is focused on urban and semi-urban areas of medium and large cities. One of the most difficult issues associated with siting of waste processing plants is its integration with local infrastructures, avoiding conflicts and negative environmental impacts at the same time. This research aims to analyse possible locations for AD plants fuelled by OFMSW in Poland. Based on the experience gained from other countries and lessons learnt from the analysis of existing facilities in Europe, conditions for the location of this type of waste treatment plants have been defined, with the focus on economic, environmental and social issues. Most likely, the results of the multicriteria decision analysis for siting of municipal solid waste AD plants (M-BIST tool) could be transferred to other countries, especially those with a comparable GDP level and a similar framework for a waste management system.
\end{abstract}

Keywords Anaerobic digestion - Organic waste - Biogas - Renewable energy · Energy from waste $\cdot$ Spatial planning $\cdot$ Siting issues

$\begin{array}{ll}\text { Abbreviations } \\ \text { AD } & \text { Anaerobic digestion } \\ \text { AHP } & \text { Analytic hierarchy process } \\ \text { EU } & \text { European Union }\end{array}$

Anna Rolewicz-Kalińska

anna_rolewicz-kalinska@is.pw.edu.pl

1 Faculty of Building Services, Hydro and Environmental Engineering, Warsaw University of Technology, Nowowiejska 20, 00-653 Warsaw, Poland

2 Faculty of Architecture, Warsaw University of Technology, Warsaw, Poland 


$\begin{array}{ll}\text { IN } & \text { Intermediate } \\ \text { MBT } & \text { Mechanical-biological treatment } \\ \text { M-BIST } & \text { Multicriteria decision analysis for siting of municipal solid waste AD plants } \\ \text { MSW } & \text { Municipal solid waste } \\ \text { NIMBY } & \text { Not in my back yard } \\ \text { OF } & \text { Organic fraction } \\ \text { OFMSW } & \text { Organic fraction of municipal solid waste } \\ \text { O\&M } & \text { Operation and maintenance } \\ \text { PR } & \text { Predominantly rural } \\ \text { PU } & \text { Predominantly urban } \\ \text { SSO } & \text { Source separated organics }\end{array}$

\section{Introduction}

Changing requirements in waste management-ever-demanding limits for the recovery and recycling on the one hand (BiPRO 2012), and waste storage restrictions on the otherhave been a driving force for the development of new and retrofits of existing waste treatment facilities (Di Maria et al. 2012). The investment process has to be carried out with a particular emphasis on modern, environmentally friendly solutions. Implementation of waste hierarchy and limitation on the fossil fuel energy consumption seem to be the most crucial environmental issues to be solved. The planning process of new locations for municipal solid waste (MSW) facilities calls for a multidimensional analysis, especially due to the legal, organisational and technical constraints (Ferretti and Pomarico 2012; Korucu and Erdagi 2012; Labiosa et al. 2013). For new investments, social and economic limitations must be seriously taken into consideration. The problem of waste treatment is also a significant social challenge in highly urbanised areas. The proximity of a treatment facility and to a waste generation point is a desired economical option (Eiselt and Marianov 2015), while inhabitants tend to prefer outermost locations due to neighbourhood reluctance and NIMBY (not in my back yard) phenomena (Hermansson 2007; Kikuchi and Gerardo 2009). Such circumstances translate into difficulties to find suitable locations for waste treatment facilities in the vicinity of medium and large cities, with a particularly high demand for such investments (Achillas et al. 2011; Generowicz et al. 2011; Khadivi and Ghomi 2012).

In Poland in 2014, there have been collected 10.3 million tons of MSW (Central Statistical Office 2015), while at the same time in the European Union (EU), $481 \mathrm{~kg}$ per capita per year of MSW are generated as average (Eurostat 2015). Poland with $268 \mathrm{~kg}$ per capita per year has the lowest waste generation quota among EU member states. Furthermore, Poland is also below the EU average in waste recycling and recovery. In the EU, MSW treatment options have been following: recycling (28\%), composting (15\%), incineration (26\%) and landfilling (15\%), which translates into $43 \%$ recycling quotas for MSW (on average across the member states). Meanwhile, in Poland landfilling is still predominant $(63 \%)$ for MSW treatment (Eurostat 2015). Biological waste treatment methods, which include AD technology, can be used to process organic fraction of municipal solid waste (OFMSW) (Jain et al. 2015), in particular for organic fraction (OF) from mixed MSW and for source separated organics (SSO understood as i.a. kitchen waste collected directly by the inhabitants) (Gellens et al. 1995). Although the biogas market in 
Poland has been analysed in a number of other literature references (Chodkowska-Miszczuk and Szymańska 2011, 2013; Szymańska and Lewandowska 2015; OniszkPopławska et al. 2014), these relate mainly to biogas from the agricultural sector. This article focuses solely on anaerobic digestion plants in Poland fuelled by OFMSW, which has not yet been the subject of a broader analysis.

The Polish legislation has set framework conditions for processing OF mechanically separated from mixed MSW at (1) mechanical-biological treatment (MBT) plants (with AD or stabilisation under aerobic conditions) or whole stream of mixed MSW (including OF) or at (2) waste incineration plants. In Poland $95 \%$ of OFMSW is treated at MBTs under aerobic conditions (Central Statistical Office 2015). Residues derived from MBTs (processing mixed waste) still have the status of waste and thus cannot be used as a fertiliser and have to be landfilled (according to national regulations in Poland). As a result of the application of $\mathrm{AD}$ at MBT plants, biogas is produced and might be converted into electricity or heat. However, as stated in the Polish law, AD process at MBTs is neither regarded as energy recovery nor qualified as a renewable energy source. This translates into lack of additional remuneration for green electricity. The situation is different in the case of incineration plants, where energy obtained in the process is accounted for as renewable proportionally to the organic fraction contained in the MSW. Nowadays, there are three MSW incineration plants: in Warsaw (outdated and undersized), Konin and Bialystok (both freshly opened); further four plants are in the final phase before starting (Poznan, Bydgoszcz, Cracow and Szczecin)—due to be completed by the first half of 2016. The capacity of the above-mentioned waste incineration plants will allow processing of $c$. $12-13 \%$ of the mixed MSW produced in Poland (assuming their full capacity). The remaining stream will be processed at MBT plants.

Another type of MSW is SSO such as kitchen and garden waste. In the analysed case studies all over Europe, SSO waste has been usually used as input material for AD or for composting as an alternative. Another type of organic waste, i.e. green waste (such as lawn/grass cuttings, tree prunings), has not been considered as an option, since ten case studies and structured interviews indicated that the application of $\mathrm{AD}$ technology is inefficient in the case of waste containing a lot of lignocellulosic biomass. Therefore, in case of SSO only kitchen waste has been included as a material for AD. The potential for SSO plants will depend mainly on the organisation and increasing involvement of inhabitants in the process of source separation, especially in the context of the requirements imposed by the EU obligations to reduce the level of landfilling of biodegradable waste to $35 \%$ (with 1995 as a baseline). In this respect, the prospects are not bright, as the separate collection of SSO in Poland has so far reached the level of only $5.6 \%$ (Central Statistical Office 2015). Further challenge is the European Commission's ambitious Circular Economy Package (2015), which includes revised legislative proposals on waste to stimulate Europe's transition towards a circular economy [COM (2015) 614 final]. The Circular Economy Package establishes a concrete and ambitious programme of action, with measures covering the whole cycle: from production and consumption to waste management and the market for secondary raw materials. Having considered above, AD technology (which has been in focus of this research) seems to be an essential link in a circular economy concept for OFMSW. By converting previously linear processes of sending OFMSW to landfill into a loop, using renewable resources for energy and making fertiliser to grow food; $A D$ is able to create new process links to form one sustainable cycle.

Considering the above, it seems that in Poland, the biggest challenge is recycling of OFMSW, in particular SSO. The project M-BIST was carried out by an interdisciplinary 
team, who studied factors that influence (positively or negatively) the location of the installation of AD using OFMSW. The analysis has been dedicated to reflect Polish conditions as well as to integration of knowledge on waste management, spatial planning and renewable energy. This article is based on the multidimensional analysis of technology choice as well as location factors in selected European countries. The research aims at identification of substantial issues determining design options for $\mathrm{AD}$ facilities using OFMSW and adapts them to specific conditions in Poland. The design options for AD technology seem to be significant for fulfilling Poland's requirements related to OFMSW recycling quotas and strengthening of the capacity to produce renewable energy.

\section{Materials and methods}

\subsection{Technological distinction}

AD technologies can be used to treat OFMSW derived from urban areas (Jain et al. 2015; Scarlat et al. 2015); as mentioned above, two main substrate streams can be distinguished:

- SSO, i.e.: kitchen and garden waste from households, green waste and catering facilities waste.

- OF selected from mixed MSW in mechanical part of MBT facilities.

Considering above statements, four basic types of waste treatment facilities based on the AD technology were defined for the purpose of this study: (1) AD at MBT plants fuelled by the OF from mixed MSW, (2) AD plants fuelled by SSO, (3) plants fuelled by SSO in codigestion in agricultural AD plants, where SSO is an admixture to agricultural substrates, (4) agricultural biogas plants (Fig. 1). Type (4) using only agriculture feedstock will not be included in further analyses, which relates to the abridged research focus of this study: use

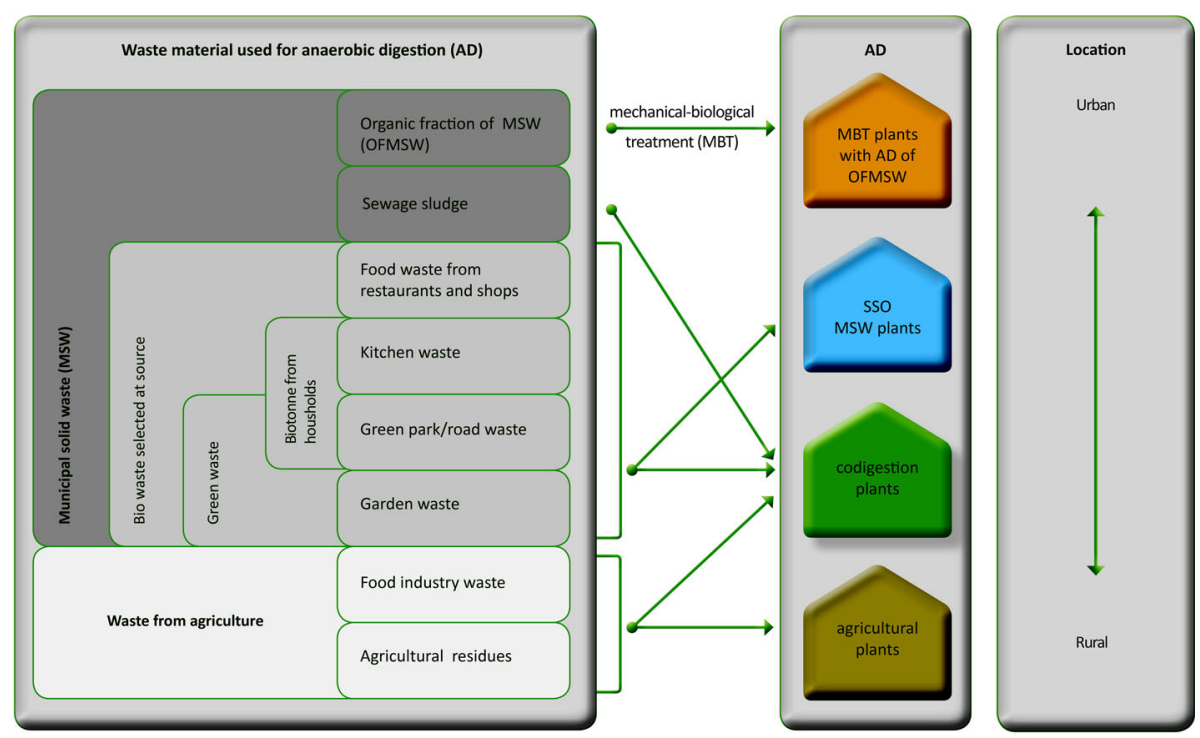

Fig. 1 Technological division of plants using OFMSW in the anaerobic digestion process 
of MSW for biogas generation. For the above-mentioned technological options, legal, economic, social and spatial context has been analysed, to formulate assumptions for further research.

\subsection{Research design and data collection methods}

The first stage of the study was to create a database of AD facilities fuelled by the OFMSW in Europe. Facilities were defined using qualitative analysis covering the following characteristics: the approximate location (state and city), the year of commissioning, technology provider, process (dry/wet AD), waste treated (SSO or OF from mixed MSW or SSO), installed capacities and energy production, and means of using biogas (Fig. 2). Literature review and reference lists provided by major AD technology suppliers were the basis of this desktop research. Key trends occurring in Europe were described based on the above-mentioned data.

The next step of the research was to analyse in detail the case studies of the European AD plants (including study visits). Ten locations were selected with the consideration of predetermined criteria. The first condition in analysed facilities was biogas production. The second one was the technological (type 1,2 and 3 AD plants) and geographical diversity (Scandinavia, southern, western and central Europe) to reflect differences in population density and GDP levels.

Below, 10 selected case studies of AD facilities located in Europe are listed, which were chosen for more detailed analyses, characterised by: location (country, region characteristics and abutting surroundings), biogas production efficiency, waste management system or management of products/by-products (breakdown into SSO and OF from mixed MSW). The case studies presented in Table 1 were chosen for more detailed analyses.

Each facility was analysed in terms of predefined criteria, divided into: spatial, organisational, technical, economic and social categories. Information was collected on the basis of structured interviews (usually face-to-face) using dedicated questionnaires. The interview data were also used to verify other European survey results. The questionnaire

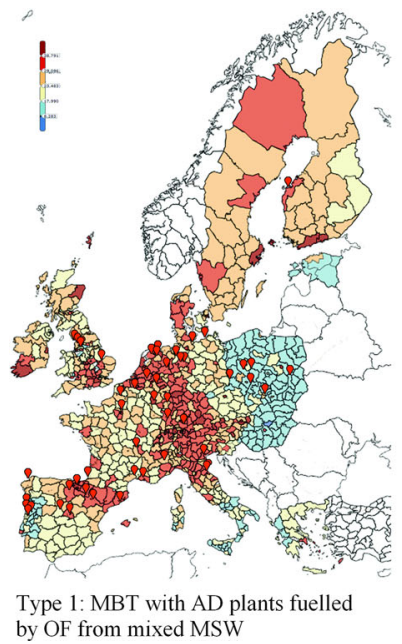

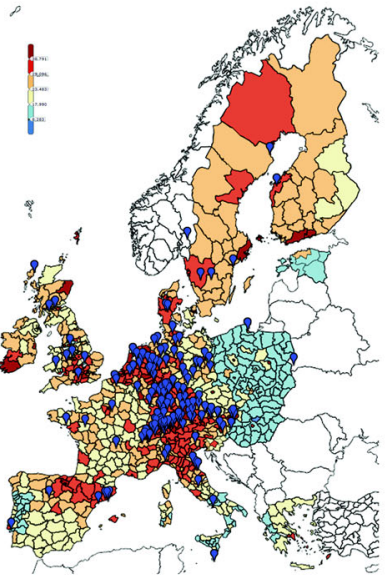

Type 2: SSO AD plants

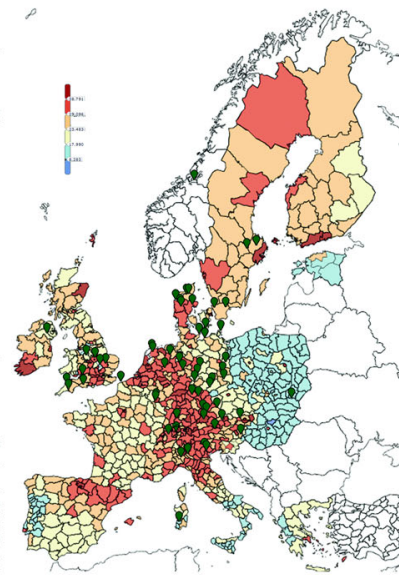

Type 3: Codigestion plants

Fig. 2 Database of European OFMSW AD plants 
Table 1 Case studies locations

Type 3: Codigestion plant

\begin{tabular}{|c|c|}
\hline \multirow[t]{2}{*}{$\begin{array}{l}\text { Type 1: MBT with AD fuelled by OF } \\
\text { from mixed MSW }\end{array}$} & $\begin{array}{l}\text { Ekopark3 Barcelona, } \\
\text { Spain }\end{array}$ \\
\hline & Gac, Poland \\
\hline \multirow[t]{6}{*}{ Type 2: SSO AD plant } & $\begin{array}{l}\text { Ekopark1 Barcelona, } \\
\text { Spain }\end{array}$ \\
\hline & Kirchstockach, Germany \\
\hline & Oslo, Norway \\
\hline & Zinasco, Alan srl, Italy \\
\hline & Zurich, Switzerland \\
\hline & Grindsted, Denmark \\
\hline \multirow[t]{2}{*}{ Type 3: Codigestion plant } & $\begin{array}{l}\text { Hellabrunn (a zoo plant), } \\
\text { Germany }\end{array}$ \\
\hline & Karpalund, Sweden \\
\hline
\end{tabular}

concerned, i.e. issues such as: (a) motivations for the development of AD technology; (b) social acceptance; (c) siting issues (serviced area, nuisance issues, extension possibilities); (d) technological issues (digestion technology characteristics, biogas production, energy production, digestate options) and (e) economic issues (operating and maintenance costs, investment costs). For each facility, a graphical analysis of the immediate vicinity using the available maps and plans was also performed (Fig. 3).

\section{Results}

\subsection{State of the art in Europe}

Currently, over $60 \%$ of the existing AD facilities in Europe, which are fuelled by the OFMSW, have been processed in the SSO mode (type 2 plants). The other two types-AD

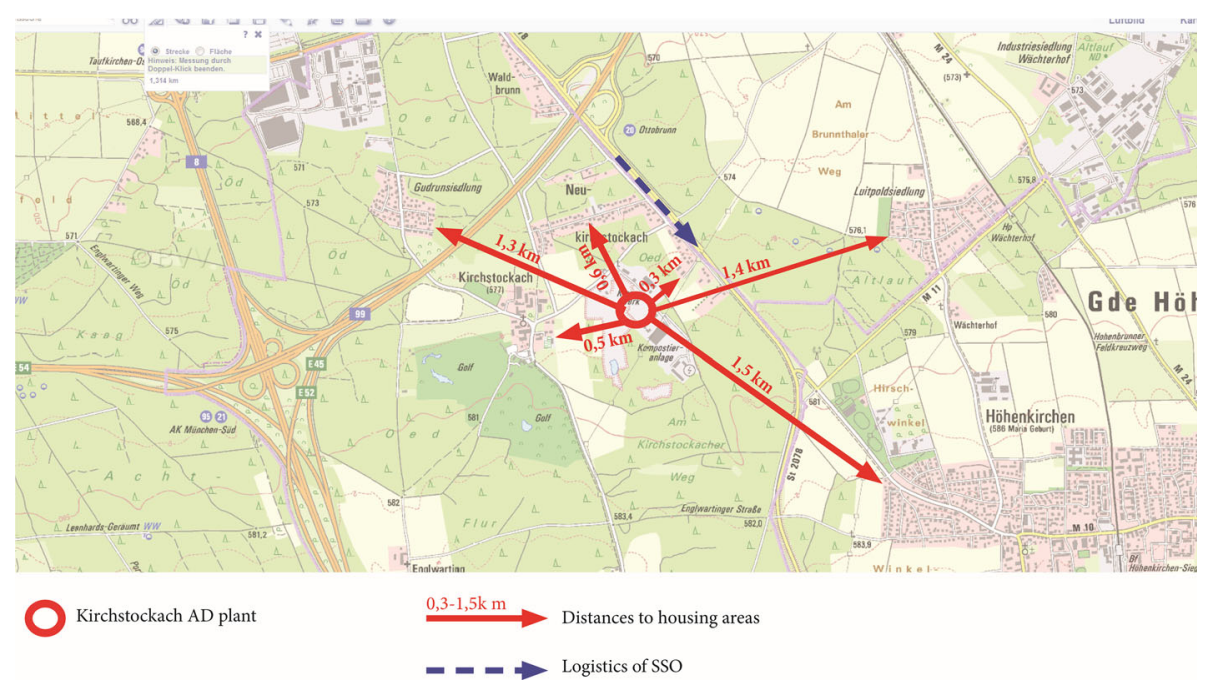

Fig. 3 Analysis of the Kirchstockach AD plant, Germany and its surroundings; own study based on the Bayern Atlas 


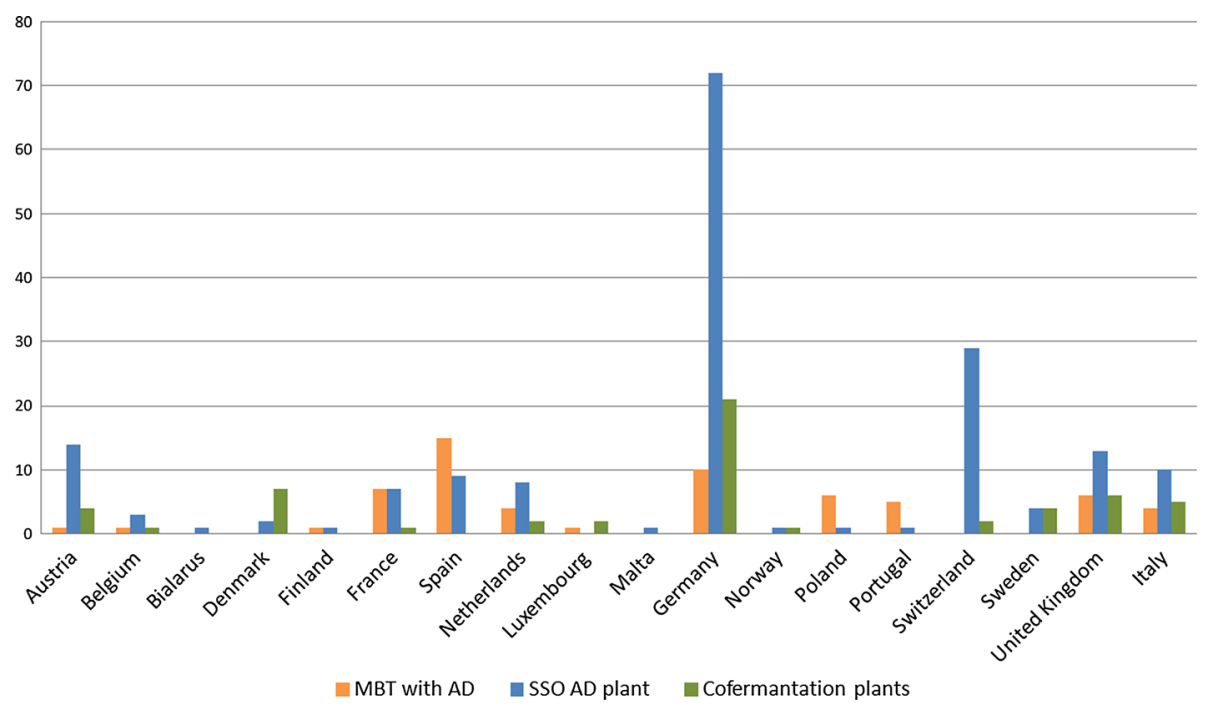

Fig. 4 Number of installations in chosen European countries (by type and of installation and by country)

as a part of an MBT (type 1) and codigestion plants (type 3) - both represent approximately $20 \%$ of the European market share. A detailed market division into plant types (1-3) in selected European countries is shown in Fig. 4.

Germany has the largest share of AD installations on the European market. There are over 100 installations with a combined processing capacity of 3 million Mg of OFMSW, of which over $70 \%$ are SSO systems. The processing capacity usually does not exceed $30,000 \mathrm{Mg} /$ year (with a few exceptions). MBT with AD, fuelled by OF from mixed MSW, were created in Germany in the past two decades, mainly between 1996 and 2007. After this period, there was a technology shift towards construction of plants using SSO.

Switzerland, Spain and UK are also significant markets for this technology. In Switzerland, type 1 installations (MBT with AD fuelled by OF from mixed MSW) are not existent. Most common are either type 2 facilities using SSO in AD process or type 3 codigestion plants. Most of them are built with processing capacity of up to 25,000 Mg/year (the average plant size is about $15,000 \mathrm{Mg}$ /year). In Spain, all facilities have been erected in the last 15 years (after 2000) and most installations are type 1 facilities. In the UK, the vast majority are type 2 systems SSO and codigestion plants also treating waste from the agri-food sector. AD plants in Spain are usually a part of the regional municipal waste management system, and the digestion process is only an element of the whole waste processing chain.

Noteworthy is the situation in Denmark, which can boast a significant capacity per capita. In recent years, no new facilities have been built; AD was added only as the capacity extension of existing ones.

The specificity of the Danish land use, including proximity of agricultural area and low population density, has resulted in predominance of type 3 codigestion plants. A feature specific to Denmark is the use of wastewater treatment plants as brownfield sites to treat $\mathrm{AD}$ of SSO to extend the existing technological chain.

Comparative historical and geographical analysis gives some insight into the development of this technology in Europe. In the early years, many of type 1 AD units (at MBTs) were built; after 2010, type 1 facilities have been erected only in chosen 
geographical locations, mainly in France, Portugal and Poland. The popularity of type 1 plants is associated with deficiency in the municipal waste collection systems (at source separate collection).

In countries with more advanced MSW collection and management system, such as the Netherlands, Germany and Switzerland, the market for type 2 AD plants has steadily grown since the beginning of the 1990s. The aforementioned data indicate that the economic situation and pro-environmental policy of a country have had a big influence on the AD technology market. In countries with advanced waste collection systems (Sweden, Austria and Germany), the emphasis is on local, small scale facilities processing waste from selective collection at source. In France and Spain (with the exception of Catalonia), where selective collection has been still too weakly encouraged, AD occurs primarily in comprehensive waste treatment systems that dominate the smaller cities of the metropolitan region (e.g. near Barcelona). These are usually large facilities requiring a reservation of suitable areas and land use planning procedures.

\subsection{Case study analysis}

\subsubsection{Organisational issues}

Analysed installations have been built over the last 20 years, the oldest facilities being Karpalund (Sweden), Grinsted (Denmark) and the Kirchstokach (Germany). Another age group, built within the last 10 years, are Hellabrunn (Germany), Ecoparc3 and Ecoparc1 (Spain). The newest group are plants in Oslo (Norway), Zurich (Switzerland), Zinasco, near Milan (Italy) and Gac (Poland, in a start-up phase). The age of an installation is important due to technological issues (technology innovation, operational experience) and social aspects (public awareness).

Involvement of local authorities has been of great importance for the successful implementation of AD facility (social acceptance and system efficiency). Most AD plants were in some way governed by the local authorities (Fig. 5). Usually, the plant operator was an entity with both private and public (city or region owned) equity. In some cases, the authorities owned the land, where the plant was located (e.g. lease agreement).

It can, therefore, be concluded that in most cases (with exception of the AD facility near Milan, which is a private entity) analysed plants have been set up as a public-private partnerships. The public involvement is important for several reasons. Firstly, in most of the European countries, municipalities own the MSW streams and decide on treatment methods. Moreover, the public equity boosts the investment process. Another issue is the public perception; investments with the participation of a local authority tend to have a higher acceptance level by the local community.

\subsubsection{Economic issues}

The research indicated that the economic aspects are the most crucial for the erection of an $\mathrm{AD}$ facility. This refers to both investment and operating and maintenance costs (O\&M). These costs are lowest in the case of codigestion of SSO (type 3 plants) (Karpalund, Grinsted). In the case of MBT plants, investment costs in the two analysed entities were in the range from 150 EUR capital cost per tonne of annual AD capacity (EUR/Mg) for Gac (Poland), to $c .230$ EUR/Mg in the case of Ecoparc3 (Spain). For the other type of plants, the capital cost varied from 55 to $300 \mathrm{EUR} / \mathrm{Mg}$ (Fig. 5). 


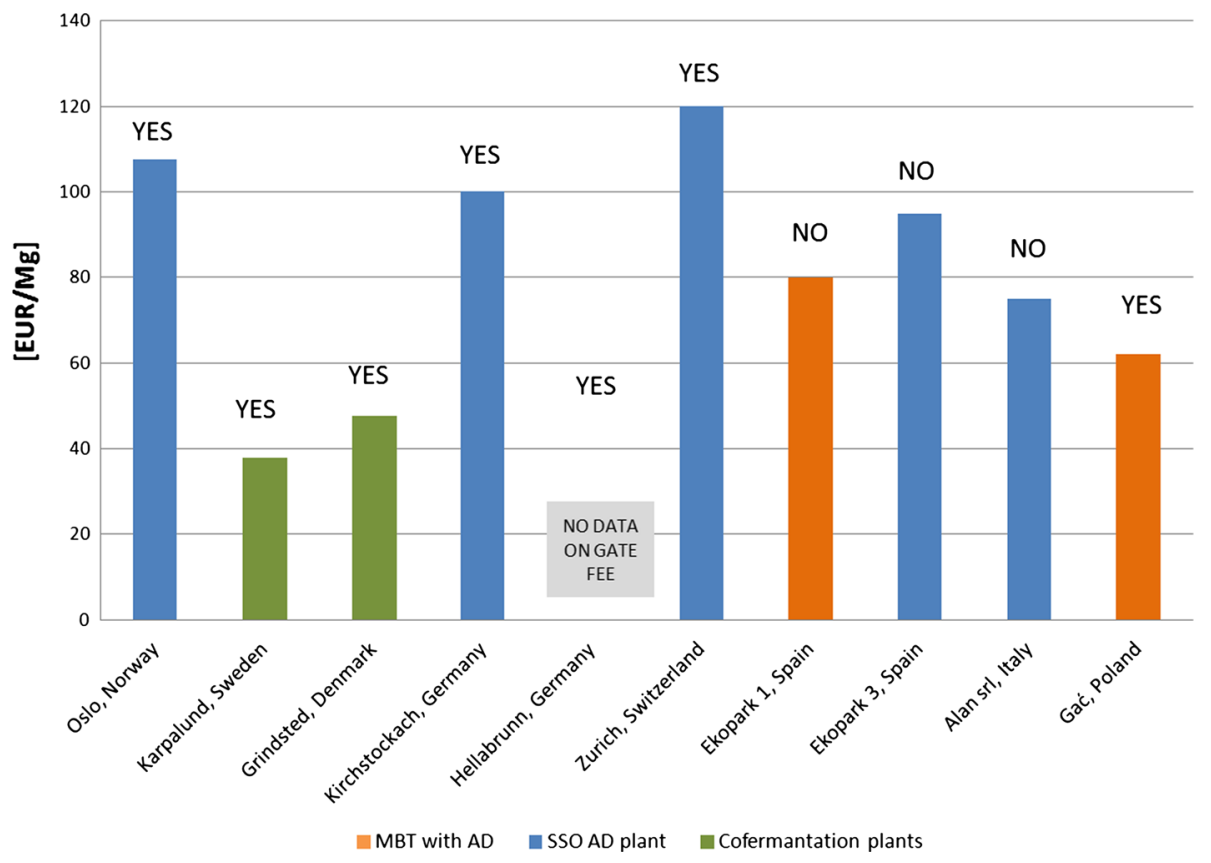

Fig. 5 Gate fee in (EUR/Mg) and the involvement of local government in the investment process (Y/N)

The economic efficiency of the AD process is mainly affected by the gate fee. Other components of the economic evaluation are remuneration for the green energy generation (income) as well as O\&M costs for waste pre-treatment and digestate after treatment. However, income generated by the renewable energy sells was discovered to be far less significant than the gate fee. In the economic accounting, the gate fee takes the first position. Costs of processing $1 \mathrm{Mg}$ of OFMSW in MBT with AD (type 1) process were estimated to be in the range of 60-90 EUR/Mg. The lowest gate fees were in the case of codigestion plants (38-48 EUR/Mg), which is in line with the analysed literature (Münster and Meibom 2011).

For AD plants processing, SSO (type 2) gate fees are in the range from $75 \mathrm{EUR} / \mathrm{Mg}$ (Milan, Italy) to 120 EUR/Mg (Zurich, Switzerland). As mentioned earlier, the O\&M costs are heavily impacted by post-treatment modes - if the digestate cannot be used for agricultural purposes (if the mixed waste is not legally allowed to be used as a fertiliser, the costs for its further treatment either by landfilling or by incineration grow dramatically).

\subsubsection{Technical issues}

The efficiency of the digestion process is the specific biogas production rate from $1 \mathrm{Mg}$ of processed OF from mixed MSW or SSO (expressed as biogas or methane yield per Mg of waste) (Fig. 6). For the analysed installations, specific biogas yields varied from 60 to $90 \mathrm{~m}^{3} / \mathrm{Mg}$. According to the literature review, average biogas yield from OFMSW has been estimated at $70-110 \mathrm{~m}^{3} / \mathrm{Mg}$ (Monson et al. 2007). The installation near Milan processing SSO has had higher than average biogas production yields $-120 \mathrm{~m}^{3} / \mathrm{Mg}$. The yield in case of codigestion plants should reflect the impact from other substrates used for 


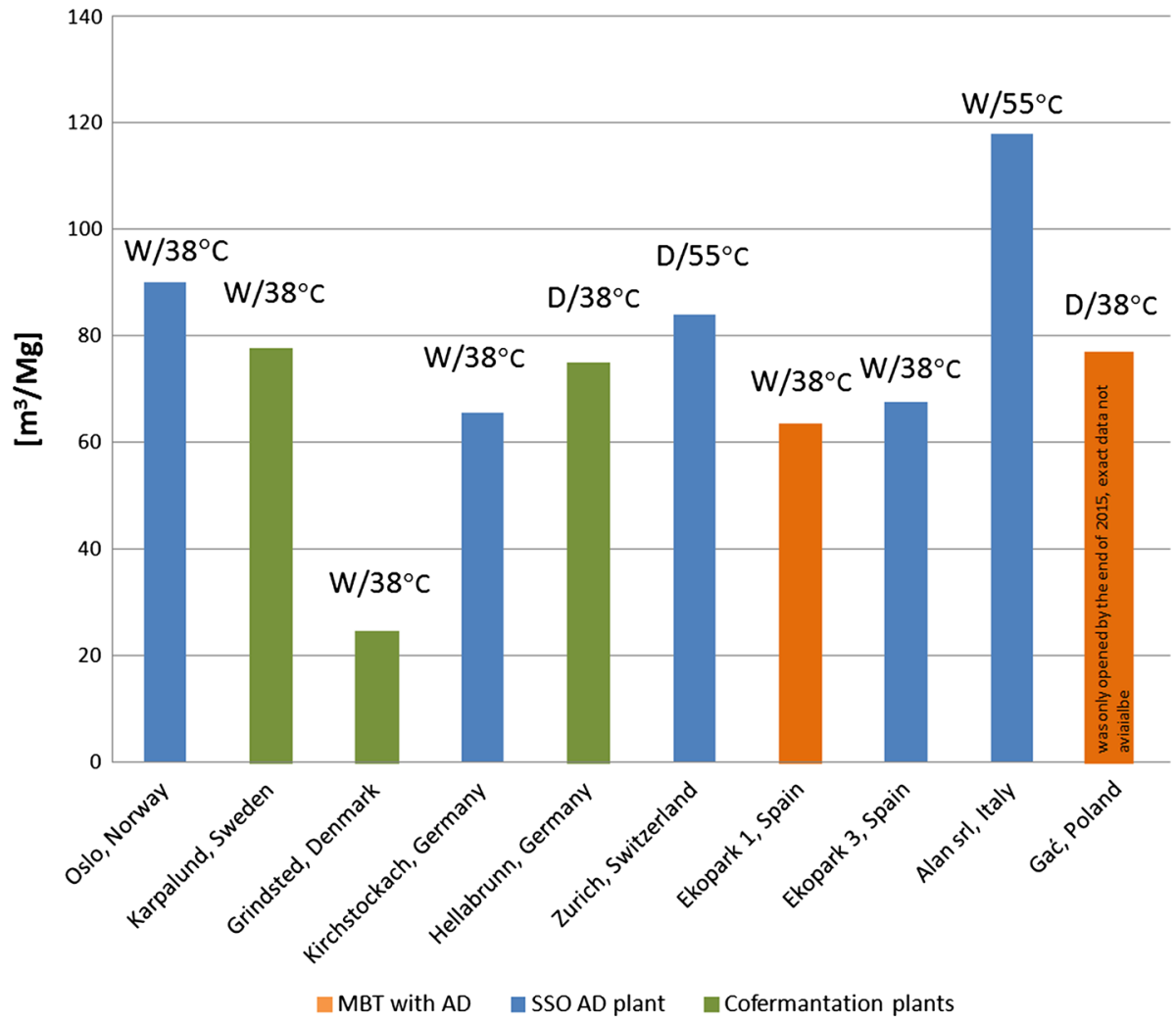

Fig. 6 Annual biogas yields $\left(\mathrm{m}^{3} / \mathrm{Mg}\right)$, type of digestion process $[$ dry $(D) /$ wet $(W)]$ and the temperature of process

digestion; for instance, in Grinsted, Denmark, it was quite low $\left(25 \mathrm{~m}^{3} / \mathrm{Mg}\right)$, as the prevailing substrate was low-energy-content sewage sludge.

There are different concepts of biogas utilisation, which is partly due to specific support system for power/heat/cooling generation from biogas in each country. In most cases, biogas is converted into electricity, which is used for plant's self-consumption, whereas the excess used for electricity generation is sold to the power grid with different accounting modes (gross or net sells). For example, in the case of installations Ecoparc1 in Spain, all electricity is sold to the grid, and the plant pays for electricity from the grid for its own use (it is more profitable because of the higher subsidies for biogas generated electricity). Most installations also produce heat, which depending on the demand is used for own purposes, sold to heating network or used otherwise, e.g. in Kirchstockach wood drying and in Ecoparc3 (Spain) for cooling.

\subsubsection{Spatial issues}

Locations have been categorised as per corresponding land use categories, i.e. OECD and Eurostat classifications for regions at NUTS3 level: predominantly rural (PR), intermediate (IN), predominantly urban (PU) and urban area near the city (PRC) (OECD 2013). 
Facilities located in Nordic countries are mainly located in urban areas (PU) and areas being transitional urban and rural area-class IN. Grinsted in Denmark is located in the rural area near the city-class PRC. MBT facility in Gac (Poland) is located on agricultural land, close to predominantly urban areas. Installations in Spain-Ecoparc1 and Ecoparc3 - are situated on the outskirts of nearly 5 million metropolis of Barcelona, i.e. in predominantly urban areas (PU).

Population density and the size of the serviced area and logistics distance are also a distinguished feature. Scandinavian plants are located in areas with a relatively low population density (80-120 inhab./ $\left.\mathrm{km}^{2}\right)$; therefore, they cover a larger waste logistics areas and thus are characterised by longer transportation distances (35-45 km radius). The Polish installation is located in the South of the country, in the area with a very low population density $\left(60\right.$ inhab. $/ \mathrm{km}^{2}$ ), which results in the longest transportation distances (with a logistics radius exceeding $60 \mathrm{~km}$ ). In contrast, Spanish plants, which are located in highly populated areas (over 700 inhab. $/ \mathrm{km}^{2}$ ), have a smaller area of service and a shorter logistics distances (15 km radius), and similar situation is in the Zurich facility (Switzerland) (Fig. 7).

Another very important issue essential for the localisation process is the evaluation of the plant's abutting surrounding. A factor that can significantly improve the siting process is the utilisation of brownfield areas, especially those that previously have been used for municipal purposes (i.e. waste or sewage treatment). Most analysed AD facilities were established at brownfield areas (equipped with technical infrastructure), i.e. at waste water treatment plants, closed landfills or composting sites.

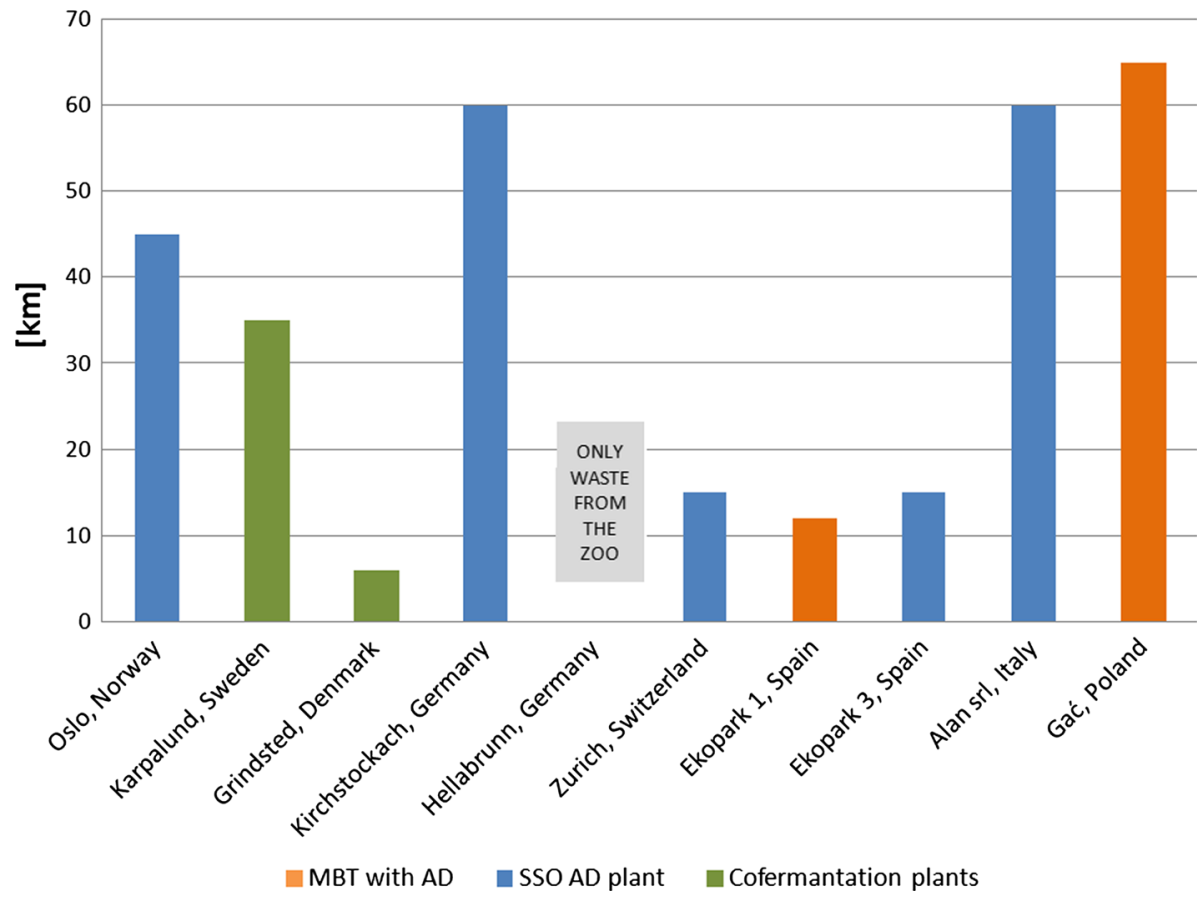

Fig. 7 Waste transportation distance $(\mathrm{km})$ 
$\mathrm{AD}$ facility located in areas already used for municipal purposes can be added to the already existing technological chain. For example in Ecoparc3 and Gac, the AD at an MBT plant is inseparable from the mechanical pre-treatment processing (crushing, separation, etc.) and post-treatment (aerobic) technologies. The facility in Gac (Poland) also includes municipal landfill site, while Ecoparc3 (Barcelona) is located in the vicinity of MSW incineration plant. Facilities fuelled with SSO (e.g. Kirstockach in Germany, Ecoparc1 in Spain) have been designed as an extension of former composting sites, and for example, Zurich investment was added to the existing waste water treatment plant.

\subsubsection{Social issues}

The main issue affecting the social acceptance of AD facility using OFMSW is its distance to inhabited areas.

The analysed facility closest to the settlements is Grindsted plant (Denmark)—here the distance is $100 \mathrm{~m}$ to existing housing area (measured distance). The unit located at the greatest distance is the $\mathrm{AD}$ at a MBT site in Gac (Poland)—almost $1 \mathrm{~km}$. From the analysis of all ten facilities, it can be concluded that the average distance ranges between 200 and $400 \mathrm{~m}$ (Fig. 8). In most cases, AD plants have gained social acceptance due to intensive educational work. Periodic complaints from local communities were recorded only in the case of Oslo (distance from buildings $400 \mathrm{~m}$ ), Kirchstockach (distance from buildings $325 \mathrm{~m}$ ) and Ecoparc3 Barcelona (distance from buildings about $300 \mathrm{~m}$ ). They were alleviated by accompanying public educational measures undertaken by a plant operator and

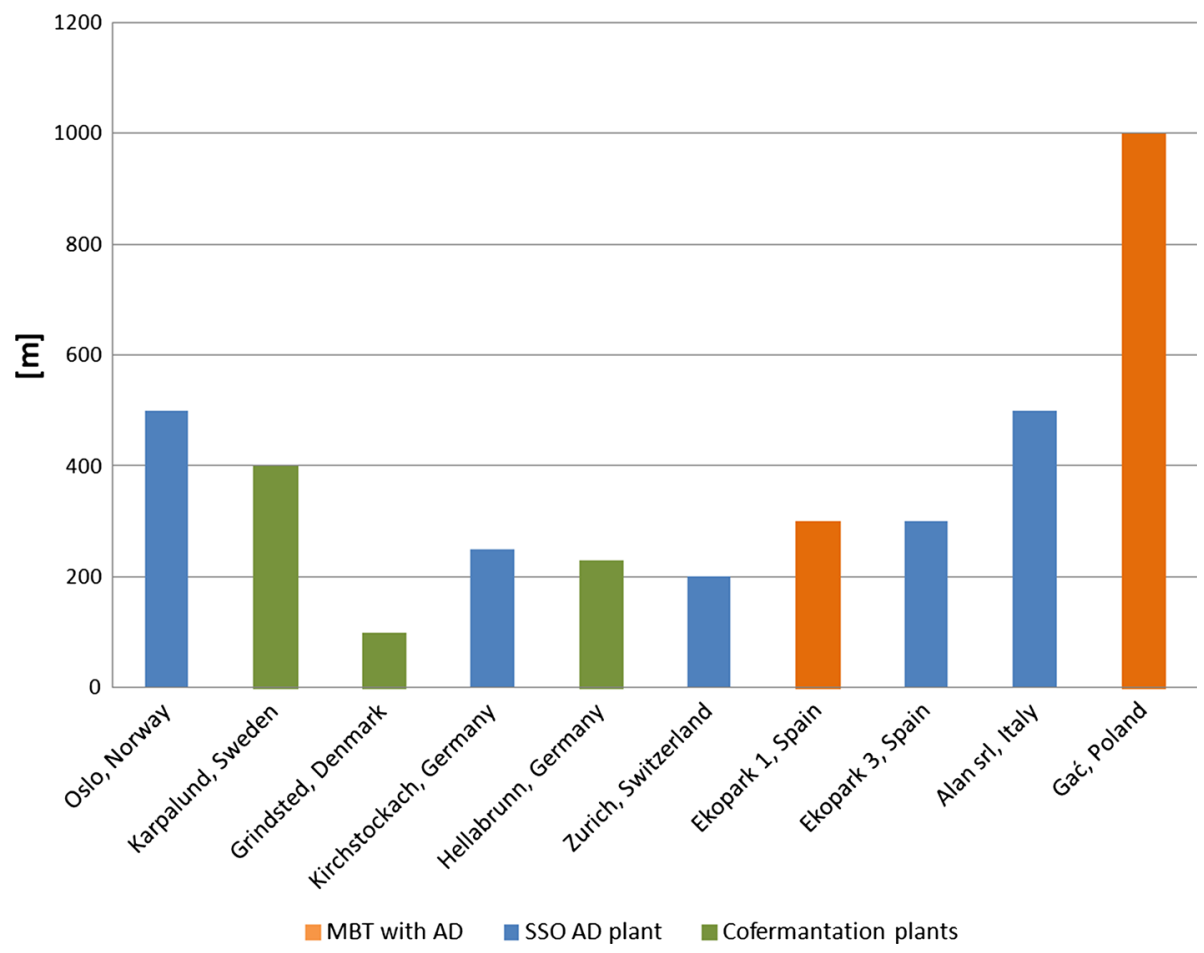

Fig. 8 Distance from built-up housing areas (m) 
local authorities. Educational activities relate to both the AD facility itself and the whole MSW management (collection) system. Examples of measures to increase social acceptance of a local community are open days, school trips, meetings, festivals. In this way, the plant operator demonstrates commitment to a local community to increase the level of trust.

A significant issue is to reduce nuisances, in particular odour emissions. This factor is particularly important in the case of plants located in the urbanised areas and can be alleviated by the application of airtight systems. Spanish installations located in the outskirts of the metropolis of Barcelona are airtight (closed halls with mechanical ventilation and deodorisation units), similarly in Zurich. The application of a highly airtight technology significantly reduces the odour nuisance and, however, increases costs. For this reason, in $\mathrm{AD}$ facility located in a distance from densely populated urban areas airtightness is not a technology option.

\section{Discussion}

The above-mentioned figures show that geographical parameters and domestic policies have a strong impact on the type of $\mathrm{AD}$ technology in urban areas. Therefore, each investment decision must be based on an individual analysis of economic, organisational, technological, spatial and social location characteristics (country and municipality level) (Antonopoulos et al. 2014; Sener et al. 2010). During the pre-investment process, the AD technology should be compared with other technology alternatives recognised for processing OFMSW such as composting or incineration (also in legal terms) (Antonopoulos et al. 2014; Tan et al. 2014).

The analysis of distribution of AD plants in Europe indicated that for European regions with higher GDP levels and with long records in separate collection, type 2 plants AD facilities treating SSO dominate. Type 1 plant systems have been recently constructed only in chosen regions, i.e. in Spain, Portugal, Poland. In countries such as Poland, with no tradition in the source separation and with lower than average GDP per capita levels, it can be expected that the dominating investments will be based on mixed OFMSW (mostly type $1 \mathrm{AD}$ at MBTs). However, with the increasing level of separate collection, type 2 plants may emerge.

Performed case studies showed that AD processes can be successfully used for the OFMSW (type 1, 2 plants), with comparable biogas yields. It is important to consider economics of such operations: logistics, pre-treatment of waste (load purification) and post-treatment (high quality digestate). AD facilities (all types) development requires appropriate economic mechanisms created by domestic policies. This mainly concerns the possibility of selling facility's by-products: electricity, heat, digestate and compost. Although a key element influencing the profitability of each waste treatment process is the gate fee, also other factors have a significant impact on the economic viability of an $\mathrm{AD}$ plant.

Barriers for the possible application of AD plants using OFMSW lie mainly in the organisational aspects (source separation, OFMSW quality, spatial conditions and involvement of local authorities) and in the economic constraints (investment and O\&M costs, the level of the gate fee, the possibility of selling energy). It seems that today the above-mentioned aspects determine the success of an AD facility in Poland. Location principles will emerge as an issue only later when the market dynamics increases. 
The performed analysis established a set of input criteria for Poland. Organic material for $\mathrm{AD}$ should be derived from a waste management region (administrative unit in Poland). In the resource analysis, crucial issues are: estimation of OFMSW streams, preliminary analysis of possible technological options and the infrastructure available in the analysed region. These basic criteria have been introduced as a pre-selection mode developed in Excel spreadsheet under the M-BIST tool.

The waste resources analysis (Fig. 9) covers two MSW streams including OF from mixed MSW and SSO. The amounts of waste are estimated using waste accumulation indicators, population density, assumed effectiveness of selective collection as per urban unit (with type and size residential area). In the case of dispersed buildings in rural areas (rural and rural-urban municipalities), the minimum population density threshold value for SSO collection has been defined at 150 inhab. $/ \mathrm{km}^{2}$ (Knappe and Vogt 2010; VHE and BGK 2009).

The criterion analysing technological alternatives (Fig. 10) includes boundary conditions related to the economics of certain technological options, expressed by the size of population within the region and the gate fee threshold values. For type 1 installations, OF from mixed MSW, the required value is $70 \mathrm{EUR} / \mathrm{Mg}$. However, for a population of more than 300,000 inhabitants, a technological option to consider is an incineration plant. In this case, however, gate fee must be higher than 95 EUR/Mg. For type 2 SSO plants, it is essential to evaluate the minimum required plant capacity, which based on the study should not be lower than 20,000 Mg/year.

The criterion analysing the available infrastructure (Fig. 11) concerns the possibility of using land exploited industrially, in particular brownfield areas. This is important for two reasons: first, such sites are already partially prepared to absorb new investments, also as the already existing industrial function will reduce the possibility of occurrence of social opposition. Particularly valuable in this case is the existing municipal infrastructure facilities (e.g. landfills, wastewater treatment plants), but also other industrial areas, e.g. agri-food processing factories or land along the railway infrastructure. Additional benefits can be expected in the case of industrial sites, e.g. the possibility to use of heat generated from cogeneration.

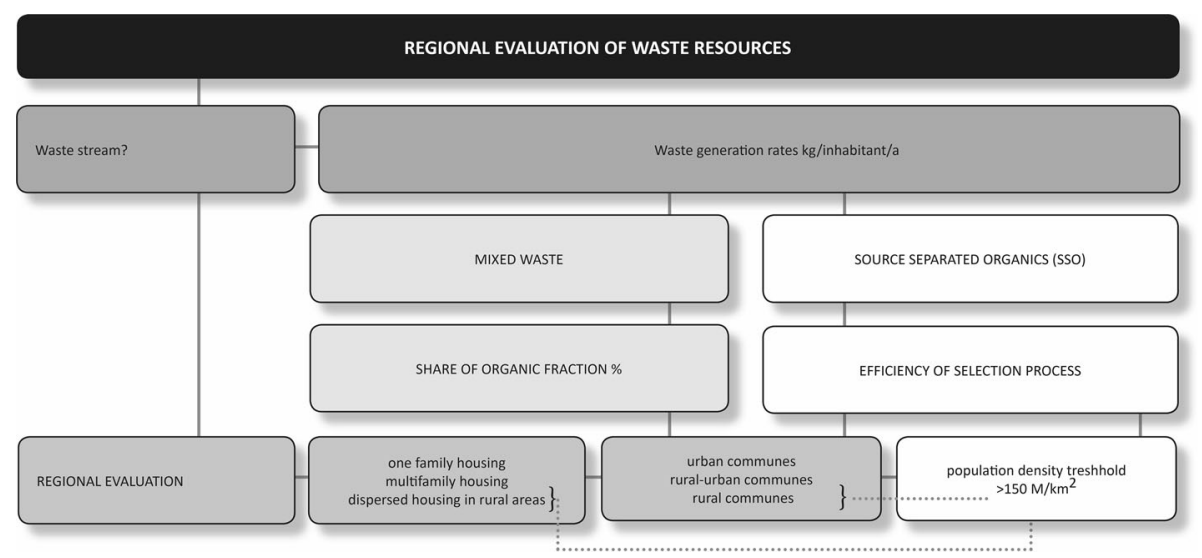

Fig. 9 Flowchart of for the input criterion characterising the volume of waste flow, own elaboration 


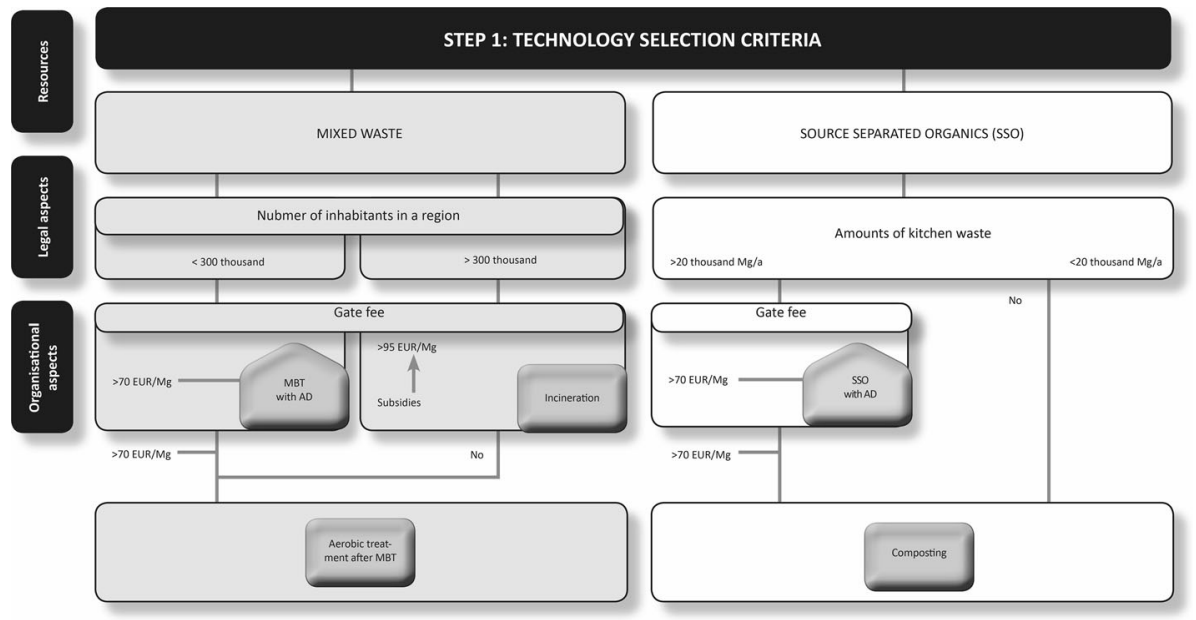

Fig. 10 Flowchart of for the input criterion characterising technological alternatives

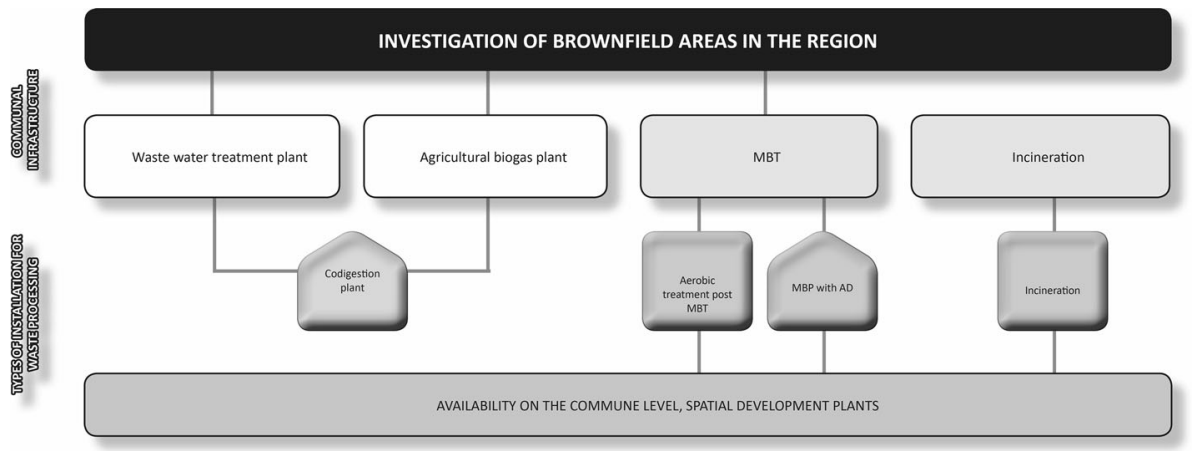

Fig. 11 Flowchart of for the input criterion characterising existing infrastructure

\section{Conclusions and further research}

The first dilemma for the future market actors in Poland (such as investors, municipalities) in the AD fuelled by the OFMSW is the technology choice. Under current legal and organisational framework in Poland, the biggest market potential lies in the development of type 1 plants (MBT with a $\mathrm{AD}$ module), mainly due to deficient separate collection system for SSO. It can be estimated, on the basis of available data (Central Statistical Office 2015; legal acts mainly Regional Waste Management Plans), that till $202030 \%$ of OFMSW will be treated anaerobically (AD) and $70 \%$ aerobically. In the best-case scenario for AD technology (as a part of MBT), this share may reach $50 \%$ in 2030.

However, in the mid-term perspective to 2030 more and more market opportunities will open to type 2 and type 3 plants, for this to take place a development of an efficient separate collection system at source (meaning directly at the household site) is inevitable. With time and increasing public awareness, more and more OFMSW will be collected directly at household site, also in Poland. By 2020, it can be estimated that the domestic 
level of separate selection of kitchen and garden waste will reach $15 \%$ share. By 2030, it is due to further increase to $c .25 \%$ on average (broken down to $c .30 \%$ in rural areas, to $c$. $40 \%$ in small towns and to $c .15 \%$ in large cities with over 50,000 inhabitants). Such shares derive from the assumptions that in highly urbanised and densely populated areas collection of SSO has been difficult due to logistics constraints, whereas households in rural areas have often been equipped with their own composters and will keep waste on their premises. The above is preconditioned by a well-functioning legal framework, strong commitment on the part of the local authorities and systematic educational activities and actions to involve community members in the process.

The market actors investigating the possibility of the implementation of the AD in Poland will also have to investigate dilemmas relevant to competitive technologies. In the case of large cities exceeding 300,000 inhabitants, a competitive technology to the type 1 $\mathrm{AD}$ (MBT with an AD unit) is the waste incineration. In this case, a decisive factor is often the level of a gate fee, availability of financial support in the form of subsidies, as well as the complexity of MSW management system (collecting and transport logistics). The analysis of the case studies (e.g. Ecoparc 3 in Barcelona) shows, however, that these two technologies often regarded as competitive can be applied at one site, especially in metropolitan areas with population exceeding 500,000 inhabitants. In the Polish case, such a hybrid option could be considered for metropol areas around major cities-Warsaw, Krakow, Lodz and Wroclaw and Silesia conurbation. Determining an appropriate plant's capacity is problematic to ensure the economic feasibility of the system. An important role in this respect can be ascribed to the use of public-private partnership, which will help reduce the risks associated with a lack of waste streams. The involvement of local authorities can be regarded as a strong added value, but on the other hand, the business experience of the private partners may be crucial to affect the profitability. It seems that the future possible implementation of such hybrid models in MSW management requires careful monitoring of the first recently commissioned incineration plants and their impact on MSW system in Poland. For plants with smaller capacity units, aerobic methods such as stabilisation or/and composting (not producing biogas) are strong competitors to the AD technology in OFMSW processing.

In conclusion, the technology choice is determined by the evaluation of market conditions; it seems that presently the key factors for determining the choice of technology are the legal framework and the investment economics. However, the market in Poland will slowly open to new AD technology investments fuelled by the OFMSW. The benefits of using biogas as an energy source and a wide range of technological solutions (including better efficiency of biogas production, reducing odour nuisance) make investors and municipalities more willing to choose AD technology as an option. Further development of this trend, however, requires a coherent policy and commitment on the site of the local and central authorities.

The siting dilemmas will emerge once the top-down policies, economic incentives and legal framework are set to encourage new investments. It seems that the potential of AD technology using OFMSW, for countries like Poland, lies in urban areas: in the vicinity of large to medium-sized cities, allowing for economical waste logistics. Only for type 3 plants (codigestion of OFMSW with agricultural materials), the potential lies in the rural areas. In all cases, the proximity to built-up housing areas is the decisive factor and usually a subject of intensive public consultations. Detailed siting procedures with the help of a multicriteria analytic hierarchy process (AHP) method are the subject of further research in the M-BIST project. 
Acknowledgments The research leading to these results has received funding from the Polish-Norwegian Research Programme operated by the National Centre for Research and Development under the Norwegian Financial Mechanism 2009-2014 in the frame of Project Contract No. (Pol-Nor/210329/46/2013), url: http:// mbist.arch.pw.edu.pl/index.php/en/.

Open Access This article is distributed under the terms of the Creative Commons Attribution 4.0 International License (http://creativecommons.org/licenses/by/4.0/), which permits unrestricted use, distribution, and reproduction in any medium, provided you give appropriate credit to the original author(s) and the source, provide a link to the Creative Commons license, and indicate if changes were made.

\section{References}

Achillas, Ch., Vlachokostas, Ch., Moussiopoulos, N., Banias, G., Kafetzopoulos, G., \& Karagiannidis, A. (2011). Social acceptance for the development of a waste-to-energy plant in an urban area. Conservation \& Recycling, 55, 857-863.

Antonopoulos, I.-S., Perkoulidis, G., Logothetis, D., \& Karkanias, C. (2014). Ranking municipal solid waste treatment alternatives considering sustainability criteria using the analytical hierarchical process tool. Resources, Conservation and Recycling, 86, 149-159.

BiPRO. (2012). Screening of waste management performance of EU member states. Report submitted under the EC project "Support to Member States in improving waste management based on assessment of Member States' performance”. Report prepared for the European Commission, DG ENV, July 2012.

Central Statistical Office. (2015). Environmental protection 2014. Statistical information and elaborations. Warsaw. ISSN 0867-3217.

Chodkowska-Miszczuk, J., \& Szymańska, D. (2011). Update of the review: Cultivation of energy crops in Poland against socio-demographic factors. Renewable and Sustainable Energy Reviews, 15(9), 4242-4247. doi:10.1016/j.rser.2011.07.126.

Chodkowska-Miszczuk, J., \& Szymańska, D. (2013). Agricultural biogas plants-A chance for diversification of agriculture in Poland. Renewable and Sustainable Energy Reviews, 20, 514-518. doi:10. 1016/j.rser.2012.12.013.

COM (2015) 614 final. Communication from the Commission to the European Parliament, the Council, the European Economic and Social Committee and the Committee of the Regions. Closing the loop-An EU action plan for the circular economy.

Di Maria, F., Sordi, A., \& Micale, C. (2012). Energy production from mechanical biological treatment and composting plants exploiting solid anaerobic digestion batch: An Italian case study. Energy Conversion and Management, 56, 112-120.

Eiselt, H. A., \& Marianov, V. (2015). Location modeling for municipal solid waste facilities. Computers \& Operations Research, 62, 305-315.

Eurostat. (2015). Eurostat news release, 54/2015-26 March 2015 available on Eurostat's website: http://ec. europa.eu/eurostat/documents/2995521/6757479/8-26032015-AP-EN.pdf/a2982b86-9d56-401c-8443ec5b08e543cc.

Ferretti, V., \& Pomarico, S. (2012). Integrated sustainability assessments: A spatial multicriteria evaluation for siting a waste incinerator plant in the Province of Torino (Italy). Environment, Development and Sustainability, 14, 843-867.

Gellens, V., Boelens, J., \& Verstraete, W. (1995). Source separation, selective collection and in reaction of biowaste. Antonie van Leeuwenhoek, 67(1), 79-89. doi:10.1007/BF00872196.

Generowicz, A., Kowalski, Z., \& Kulczycka, J. (2011). Planning of waste management systems in urban area using multi-criteria analysis. Journal of Environmental Protection, 2011(2), 736-743. doi:10. 4236/jep.2011.26085.

Hermansson, H. (2007). The ethics of NIMBY conflicts. Ethical Theory and Moral Practice, 10, $23-34$. doi:10.1007/s10677-006-9038-2.

Jain, S., Jain, S., Wolf, I. T., Lee, J., Wah, Y., \& Tong, A. (2015). Comprehensive review on operating parameters and different pretreatment methodologies for anaerobic digestion of municipal solid waste. Renewable and Sustainable Energy Reviews, 52, 142-154.

Khadivi, M. R., \& Ghomi, F. (2012). Solid waste facilities location using of analytical network process and data envelopment analysis approaches. Waste Management, 32, 1258-1265.

Kikuchi, R., \& Gerardo, R. (2009). More than a decade of conflict between hazardous waste management and public resistance: A case study of NIMBY syndrome in Souselas (Portugal). Journal of Hazardous Materials, 172(2-3), 1681-1685. 
Knappe, F., \& Vogt, R. (2010). Optimierung der Erfassung und Verwertung von Bio- und Grünabfällen in Baden-Württemberg. LUBW Landesanstalt für Umwelt, Messungen und Naturschutz Baden-Württemberg, 115. http://um.baden-wuerttemberg.de/fileadmin/redaktion/dateien/Altdaten/202/Anlage_ Leitfaden_Bioabfall.pdf.

Korucu, M. K., \& Erdagi, B. (2012). A criticism of applications with multi-criteria decision analysis that are used for the site selection for the disposal of municipal solid wastes. Waste Management, 32(12), 2315-2323.

Labiosa, W. B., Forney, W. M., Esnard, A.-M., Mitsova-Boneva, D., Bernknopf, R., Hearn, P., et al. (2013). An integrated multi-criteria scenario evaluation web tool for participatory land-use planning in urbanized areas: The Ecosystem Portfolio Model. Environmental Modelling and Software, 41, 210-222.

Monson, K., Esteves, S., Guwy, A., \& Dinsdale, R. (2007). Anaerobic digestion of biodegradable municipal wastes: A review. Newport: Sustainable Environment Research Center SERC. ISBN 978-1-84054-1571.

Münster, M., \& Meibom, P. (2011). Optimization of use of waste in the future energy system. Energy, 36, $1612-1622$.

OECD. (2013). OECD regions at a glance. Paris: OECD Publishing. doi:10.1787/reg_glance-2013-en.

Oniszk-Popławska, A., Matyka, M., \& Dagny, R. E. (2014). Evaluation of a long-term potential for the development of agricultural biogas plants: A case study for the Lubelskie Province, Poland. Renewable and Sustainable Energy Reviews, 36, 329-349. doi:10.1016/j.rser.2014.04.010.

Scarlat, N., Motola, V., Dallemand, J. F., Monforti-Ferrario, F., \& Mofor, L. (2015). Evaluation of energy potential of municipal solid waste from African urban areas. Renewable and Sustainable Energy Reviews, 50, 1269-1286.

Sener, S., Sener, E., \& Karagüzel, R. (2010). Solid waste disposal site selection with GIS and AHP methodology: A case study in Senirkent-Uluborlu (Isparta) Basin, Turkey. Environmental Monitoring and Assessment, 173, 533-554. doi:10.1007/s10661-010-1403-x.

Szymańska, D., Lewandowska, A. (2015). Biogas power plants in Poland-structure, capacity, and spatial distribution. Sustainability, 7, 16801-16819.

Tan, S., Hashima, H., Leea, Ch., Taiba, M., \& Yan, J. (2014). Economical and environmental impact of waste-to-energy (WTE) alternatives for waste incineration, landfill and anaerobic digestion. Energy Procedia, 61, 704-708.

Verband der Humus Erdenwirtschaft e. V. (VHE), Bundesgütegemeinschaft Kompost e. V. (BGK). (2009). Studie Einführung und Optimierung der getrennten Sammlung zur Nutzbarmachung von Bioabfällen. BGK e.V., VHE e.V., 72. http://www.kompost.de/uploads/media/Handbuch_Bioabfallsammlung_06_ 09.pdf. 